\title{
Management of Tumors of the Cerebellopontine Angle in Developing Countries: Experience of Fann Teaching Hospital in Dakar
}

\section{ISSN: 2637-7748}

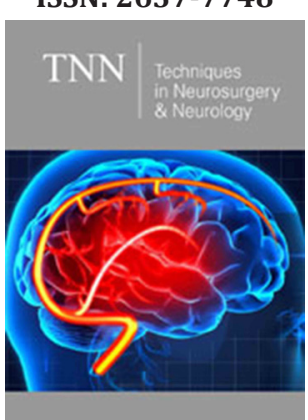

*Corresponding author: Mbaye $\mathrm{M}$, Department of Neurosurgery, Dakar, Senegal

Submission: 价 July 17, 2019

Published: 非 November 01, 2019

Volume 3 - Issue 1

How to cite this article: Mbaye $M$ Thiam A, Mulumba I, Fahad A, Thioub $\mathrm{M}$, et al. Management of Tumors of the Cerebellopontine Angle in Developing Countries: Experience of Fann Teaching Hospital in Dakar. Tech Neurosurg Neurol.3(1). TNN.000552.2019.

DOI: $10.31031 /$ TNN.2019.03.000552

Copyright@ Mbaye M, This article is distributed under the terms of the Creative Commons Attribution 4.0 International License, which permits unrestricted use and redistribution provided that the original author and source are credited.

\author{
Mbaye M*, Thiam AB, Mulumba IR, Fahad A, Thioub M, Sy ECN, Faye M, Ndoye \\ N, Ba MC and Badiane SB
}

Department of Neurosurgery, Senegal

\begin{abstract}
Introduction: Cerebellopontine angle (CPA) tumors account for about 5 to $10 \%$ of intracranial tumors in the literature. The majority of lesions in this region are benign, so surgery is the main treatment. The literature on the management of these lesions is poor in our context. In this way, we will draw up the epidemiological profile and analyze the diagnostic, therapeutic and evolutionary aspects of this pathology in Dakar.
\end{abstract}

Materials and methods: This is a retrospective study of 51 patients hospitalized in the neurosurgery department of the FANN teaching hospital for the management of the CPA tumors, from January 2007 to December 2018.

Results: CPA tumors accounted for $2.8 \%$ of intracranial tumors. The average age was 43.4 years and the sex ratio was 0.8 . The main signs found were: vestibulo-cochlear syndrome in $66.7 \%$ of cases, cerebellar syndrome in $66.7 \%$ and HIC syndrome in $56.9 \%$ of cases. On imaging, the average size of the tumor was $4.8 \mathrm{~cm}$. The most common tumor was meningioma. Hearing loss and facial paralysis were the most common sequelae. The most common complications are infectious.

Conclusion: The tumor pathology of CPA is essentially composed of benign tumors, but of large size in our context making the management of its lesions delicate. Surgery is the main prognostic element found.

Keywords: Cerebellopontine angle; Meningioma; Dakar

\section{Introduction}

Tumors of the cerebellopontine angle (CPA) represent about $10 \%$ of intracranial tumors in adults and about $1 \%$ in the pediatric series. The most common histological types are vestibular schwannoma, meningioma and squamous cyst. These three tumors represent more than $90 \%$ of the tumors of the cerebellopontine angle. These are essentially benign lesions [1-4]. Surgical removal is the mainstay of treatment, moving from the era of preservation of the vital prognosis to the era of preservation of the functional prognosis. To date, the literature on CPA tumor surgery is uncommon in our developing countries where access to care is late and the technical platform is not sufficient $[5,6]$. Thus, our objective is to report our experience on this pathology; we will establish the epidemiological profile and analyze the diagnostic, therapeutic and evolving aspects of this pathology in our context in Senegal.

\section{Materials and Methods}

We conducted a descriptive study, with retrospective data from January 2007 to December 2018, a 12-year period. The study was conducted at the neurosurgical department of the FANN National University Hospital. We have included in the study all patients who have had clinical examination and medical imaging (CT scan or brain MRI) for an accurate topographic diagnosis of cerebellopontine angle tumor. We have excluded incomplete records, tumor lesions of the anterior or middle floor of the skull base extended to the cerebellopontine angle and airway lesions extended to the cerebellopontine angle. We also excluded brainstem and cerebellar lesions spread at the cerebellopontine angle. The parameters evaluated were epidemiological, clinical, paraclinical, therapeutic and evolving. Data analysis was performed on EXCEL 2016 and the statistical analysis software "SPSS statistics 20". 
Results

\section{Study population}

During the study period, we reported 51 cases of cerebellopontine angle tumors on 1805 intracranial tumors, representing $2.8 \%$ of all intracranial tumors. The mean age of the patients was 43,4 years, with extremes ranging from 1 year to 77 years. The most represented age group was 41 to 65 years, representing $45.1 \%$. The sex ratio of our series was 0.8 .

\section{Clinical aspects}

The average consultation time was 8.8 months with extremes between 15 days and to 3 years. Headache was the most common cause of consultation, accounting for $82.4 \%$ of cases. $45.1 \%$ of patients complained of hearing loss. The examination of clinical signs was dominated by cerebellar syndrome (66.7\%), vestibulocochlear syndrome (66.7\%) and intracranial hypertension syndrome (56.9\%). Figure 1 illustrates the impairment of the cranial nerves.

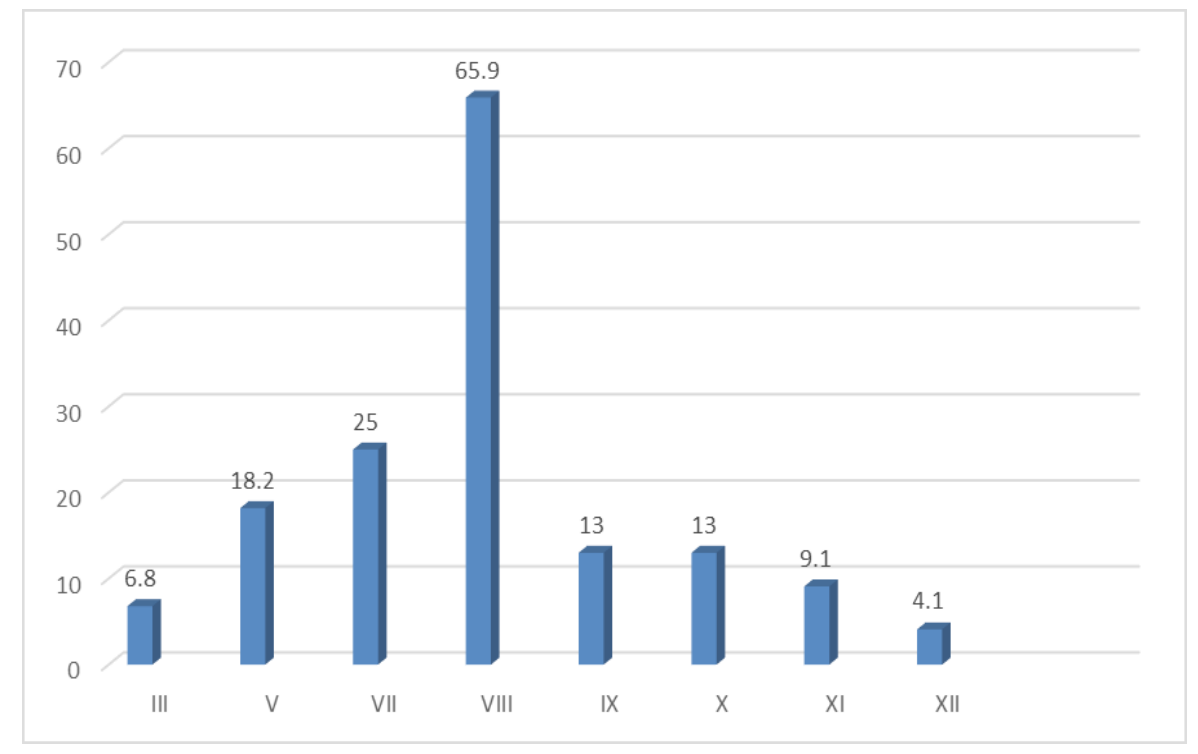

Figure 1: Summary percentage rate of cranial nerve damage.

\section{Paraclinical aspects}

All our patients have had, at least, a morphological exploration. Cerebral CT was performed in $74.5 \%$ of patients (Figure $2 \& 3$ ) and cerebral MRI was performed in $37.3 \%$ of patients and both investigations were performed in $11.8 \%$ of patients. The average tumor size was $5.2 \mathrm{~cm}$ with extremes from $2 \mathrm{~cm}$ to $8.9 \mathrm{~cm}$. Associated hydrocephalus was found in $72.7 \%$ of cases. No neurophysiologic exploration has been carried out.
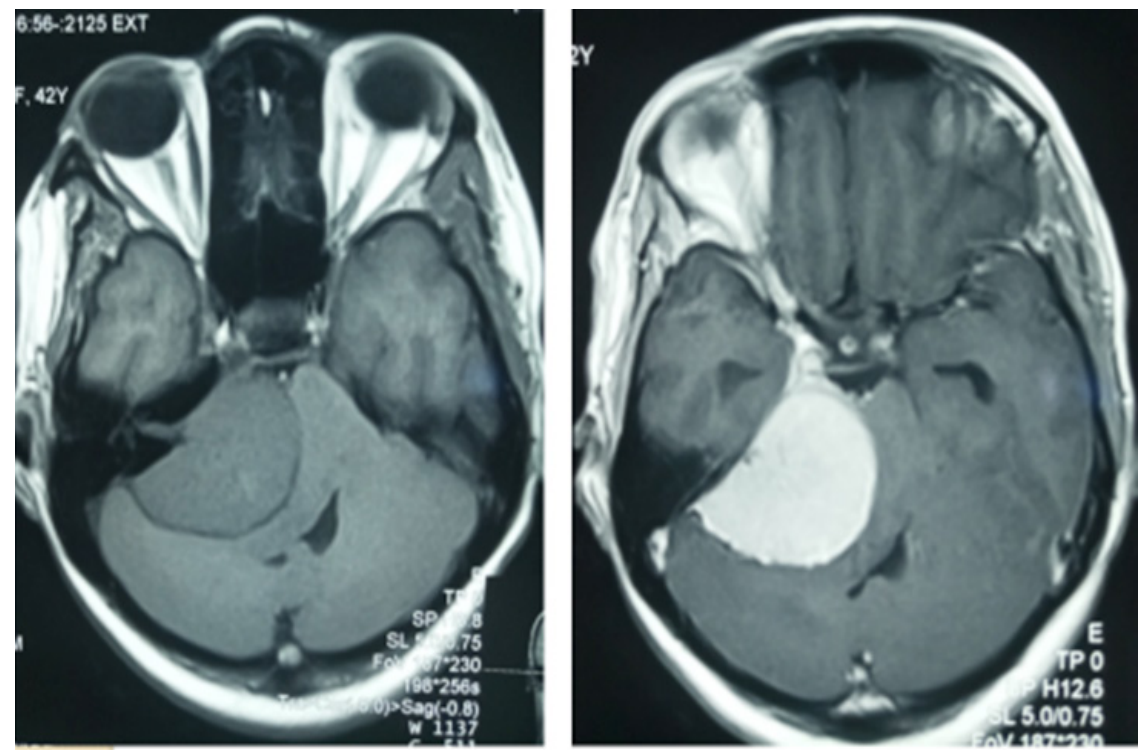

Figure 2: Injected T1 and T1 brain MRI sequences showing a meningioma of the right APC with a significant mass effect on the brain stem and 4 th ventricle. 

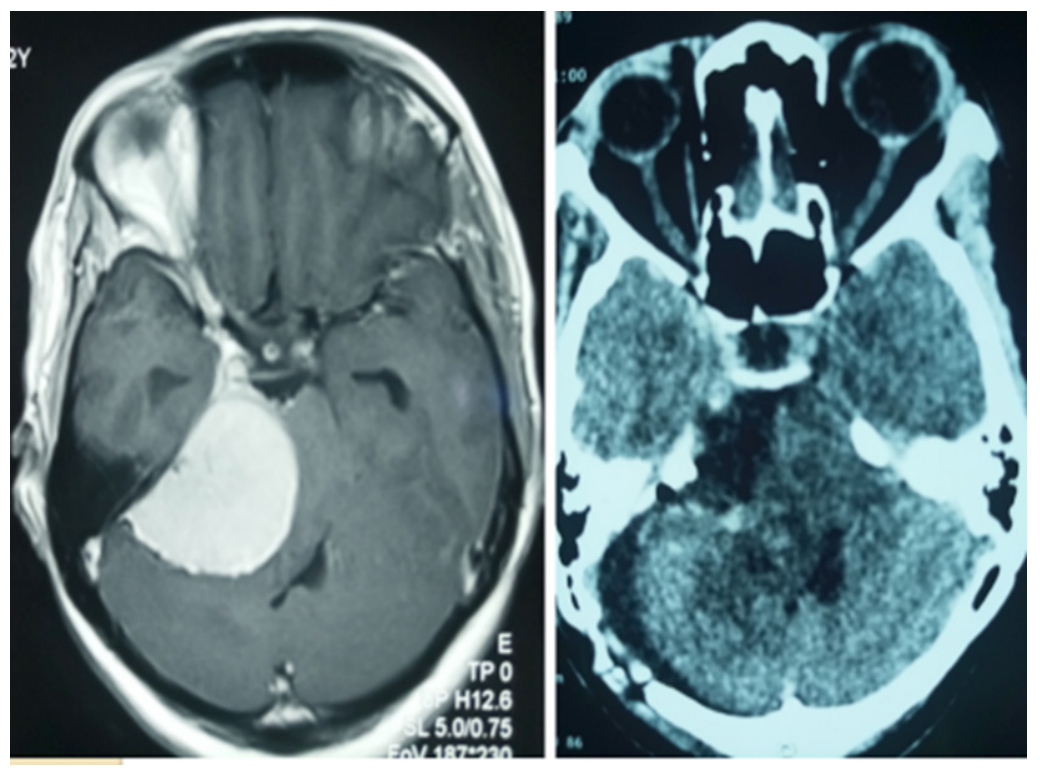

Figure 3: Cerebral CT at day 4 post-exeresis of a meningioma of the right CPA.

\section{Therapeutic aspects}

Surgery was performed in 48 patients (94.1\%). There were 2 cases of surgical abstention and 1 case of radio clinical surveillance. Gross total resection was performed in $35.3 \%$ of the cases, the retro sigmoid approach was the most common, and accounting for $70.6 \%$ of cases and $49 \%$ of patients received a CSF shunt. The average duration of removal surgery was 4.7 hours with extremes of 3 hours to 8.2 hours. One of our patients received radiotherapy and chemotherapy.

\section{Evolving aspects}

The average length of hospitalization was 27 days with extremes ranging from 4 days to 2.5 months. The average follow-up was 6 months ( 1 month-4 years). We reported 7 cases of death or $20.5 \%$ of cases. There were 4 cases of recurrence, representing $11.8 \%$. The complications (Table $1 \& 2$ ) identified in our series were: cranial nerve involvement, infections, CSF leaks, hydrocephalus and a hematoma of the surgical site.

Table 1: Distribution according to histological results.

\begin{tabular}{|c|c|}
\hline Meningioma & 5 \\
\hline squamous cyst & 2 \\
\hline medulloblastoma & 2 \\
\hline hemangioblastoma & 1 \\
\hline schwanoma vestibular & 1 \\
\hline high grade glioma & 1 \\
\hline
\end{tabular}

Table 2: Distribution by post-surgical complications (\%).

\begin{tabular}{|c|c|}
\hline Cranial nerve injury (VII+++) & $26,3 \%$ \\
\hline Infections & $26,3 \%$ \\
\hline hydrocephalus & $11,8 \%$ \\
\hline CSF leak & $8,8 \%$ \\
\hline Hematoma & $5,9 \%$ \\
\hline
\end{tabular}

\section{Discussion}

\section{Frequency}

The literature on CPA tumors as a whole is rare. Most studies focus on specific histological types, especially on vestibular schwanoma and meningioma. These two tumors represent approximately $80 \%$ and $10 \%$ of the CPA tumors of the different series [7-10] respectively. During a 13-year study period in Nigeria, out of 612 cases of intracranial tumors, [6]. In a South African study, had an annual prevalence of 115 cases of vestibular schwanoma [11]. In this study, there were only 3 cases of black patients, in contrast to the high number of Caucasian patients. This finding is similar to other South African and American studies. It indicates a low prevalence of vestibular schwanoma in black populations [5]. In our study, tumors of CPA represent $2.8 \%$ of intracranial tumors. This rate is low compared to the data in the literature. It suggests a low frequency of CPA tumors in our context. Of the 44 patients, collected between 2007 and 2017, 12 cases had an aspect to vestibular schwanoma imaging $(27.3 \%)$. These results are similar to the South African and Nigerian series. They reflect the low prevalence of schwanoma in sub-Saharan populations. As vestibular schwanoma is the main tumor of CPA, its low prevalence in our population could be an element of explanation for the relative rarity of CPA tumors in our regions.

\section{Age and sex}

Female predominance is the most common in many series $[12,13]$. The average age was between the 4 th and 5 th decade in the different series [9,12,14-16]. We found an average age of 43 years, which is in line with the published data.

\section{Clinical aspects}

The median consultation time was 44.4 months in the series of 1000 cases of vestibular schwannoma by Samii et al. in Germany [14]. Talfer et al. [16] found an average delay of 26 months in France [16] and 25 months for Voss et al. [13] on a series of 24 meningioma 
cases. Our results are in accordance with the literature, the long consultation time is explained by the reason that otological symptomatology rarely leads patients to consult. They come in the stages of neurological signs. In most occidental series, vestibulocochlear symptomatology is the most common with hearing loss and vertigo $[9,10,12,14-20]$. In our series, cerebellar signs, signs of intracranial hypertension and involvement of the long pathways predominated as well as vestibulo-cochlear symptomatology. This is due to the fact that our series is mainly composed of large tumors.

\section{Paraclinical aspects}

As with all current series, all patients have had a CT scan or/ and brain MRI to diagnose tumors of the cerebellopontine angle. Both explorations were performed in all patients in the current series. In our series, cerebral CT is the most performed radiological exploration, $77.3 \%$ benefited from it. The facility to perform CT scan and its accessible cost compared to MRI makes it the most requested exam in our context. The size of the tumors in our series being large or medium, brain CT had a good sensitivity. However, the gold standard for exploring a suspected pathology of CPA is brain MRI. CPA meningioma was the most common tumor. On the other hand, in the occidental series, there is a clear predominance of vestibular schwanoma in this location. They represent more than $80 \%$ of CPA tumors and meningioma represents 5 to $10 \%$. This difference is explained by the fact that our series is mainly composed of sub-Saharan patients. Indeed, in South Africa, of a series of 95 cases of vestibular schwanoma, Seedat et al. [11] found only 3 black patients. In Nigeria, in a series of 612 cases of intracranial tumors, Ohaegbulam et al. [6] had only 3 cases of vestibular schwanoma. The same team had 252 cases of intracranial meningiomas out of 612 cases. Meningioma is reported to represent the most common tumor in their area. Regarding the size of the tumor, we found an average size of $5.2 \mathrm{~cm}$. Only 2 cases out of $51 \mathrm{CPA}$ tumours were less than $3 \mathrm{~cm}$ in size. Thus, our series was essentially composed of large or giant tumors. In contrast, in the Occidental series, there is a predominance of stage II and III tumors [14,21-23].

This predominance of large tumors in our series is explained by the delayed diagnosis. Indeed, the lack of a technical platform and specialists in our regions does not allow for early diagnosis. Otological investigations are necessary for the preoperative and postoperative evaluation of patients with APC tumors in the current series [24-29]. The preservation of hearing is one of the challenges of CPA surgery [5]. No patients have had an otological examination in our series. This is a pitfall in the objective evaluation of preoperative and post-operative cochlear involvement.

\section{Therapeutic aspects}

In Algeria, out of a series of 151 unilateral vestibular schwanomas with a major axis in the CPA between 30 and $60 \mathrm{~mm}$, all patients underwent retro sigmoid surgery [20]. In South Africa, out of a series of 115 cases, the retro sigmoid pathway was used in $53 \%$ of cases, the trans labyrinthine pathway in $8 \%$ of cases and the subtemporal pathway (supra petrous) in 7\% of cases [11]. In Germany, Samii and Coll operated on 4000 cases of vestibular schwannoma retro sigmoidally [7]. Results are more dependent on the surgeons' experience than on the advantages or disadvantages of a particular approach. Excellent results in terms of complete removal rates and functional preservation of facial nerve function have been achieved in hands experienced with each of these approaches.

In the literature, the quality of excision varies according to the histological nature and size of the tumor [22,30]. In the Maghreb, Boublata had $83 \%$ of gross total resection on series of vestibular schwanomas [20]. Sekhar and Samii found respectively 99 and $98 \%$ gross total resection on schwannoma series $[9,29]$. The same authors, Sekhar and Samii, found a rate of $56 \%$ and $85 \%$ of gross total resection, respectively, on CPA meningioma series [10]. Agawarl, Ari J. Kane, and Nakamura found 50\%, 54\% and 85.9\% gross total resection, respectively, in contemporary series of CPA meningiomas $[15,22,30]$. In our series, we only had $35.3 \%$ gross total resection. This is due to the fact that most of our series consists of large tumors (greater than $5 \mathrm{~cm}$ ); without intraoperative monitoring, the tumor portions adhering to the cranial nerves and brainstem was not removed. This attitude allows us to reduce the morbidity of the surgery. All our patients have been operated on under an operating microscope, but the lack of drills makes it difficult to properly approach these lesions.

Hydrocephalus was present in $72.7 \%$ of our patients at admission. This high frequency is explained by the large number of tumors larger than $4 \mathrm{~cm}$ in our series. CSF diversion was performed in $52 \%$ of patients. Out of a series of 400 cases of Samii et al. [29] 53 patients had preoperative hydrocephalus, 48 of the 53 patients received removal surgery, $11.3 \%$ of patients required additional hydrocephalus treatment [29]. Pirouzmand F et al. [31] of 284 patients with CPA tumors, they found 39 cases of hydrocephalus; only 4 required an emergency diversion [31]. Our high frequency of derivation is explained by the reason that most patients are coming to a table of intracranial hypertension.

Radiosurgery is becoming a non-invasive alternative for most CPA tumors, such as schwanomas and meningiomas smaller than $2 \mathrm{~cm}[25,27,28,32,33]$. Not having this technique in Senegal, no patient has had radiosurgery in our series. In our study context, standard radiotherapy is available, it is mainly indicated for malignant tumors. Chemotherapy is primarily indicated as an adjunct to removal surgery for WHO grade III or IV tumors. We had a single case of desmoplastic medulloblastoma that benefited from it.

\section{Evolutionary aspects}

Low or no mortality is found in most current series $[12,16]$. We had a high rate $(20.6 \%)$ compared to the results of the literature. This is explained by the high prevalence of large tumors increasing the morbidity and mortality of procedures and by the unavailability of intraoperative monitoring. Patel et al. [12] out of a multicenter series of 14,928 patients in the USA, $10.1 \%$ had post-operative facial involvement [12]. In Germany, out of a series of 1000 cases, Samii et al. [29] had 45\% facial paralysis [29]. The preservation of the facial nerve is one of the challenges of this surgery, not having monitoring of this nerve intraoperative, our attitude was very conservative. 
Indeed, the tumor portion very adherent to the facial nerve were not removed. This attitude allowed us to have $11.8 \%$ postoperative involvement. Concerning the damage to the cochlear nerve, it is the most affected nerve preoperatively in the pathology of CPA. In our series, without an objective pre-operative and postoperative evaluation, it is difficult to have an exact assessment of the postoperative outcome. Samii had 3\% of meningitis out of a series of 1000 cases [29]. Patel et al. [12] found $0.4 \%$ out of 14,928 cases [12]. We had $5.8 \%$ of meningitis cases. This is a classic complication of surgery but decreases with the experience of the teams. CSF leaks are a common complication of CPA surgery. But only a few cases require surgical management.

Samii et al. [29] had 9.2\% fistulas per 1000 operated patients [29]. Patel et al. had $3.4 \%$ fistula in 14,928 patients [12]. Our results are similar to those in the literature. In our study, one patients had a hematoma at the surgical site; and required surgery to evacuate the hematoma. Samii et al. [29] had 22 cases, 15 of which required evacuation [29]. Patel recorded 1.6\% hematoma [12]. Hematomas are a serious postoperative complications, they represent, together with diffuse posterior cerebral fossa edema, the main causes of delayed awakening. Thus, a control CT scan is imperative before any delay in waking up.

CPA meningiomas recur more often, compared to vestibular schwanomas. Recurrence is correlated with the quality of meningioma removal (SIMPSONS) and histological grade. Indeed, Agaward et al. [22] on a recent series of 24CPA meningiomas, observed 3 cases of recurrence; all three had had subtotal excision and two had grade II meningioma [22]. In our series, no cases of meningiomas or schwanomas have recurred. However, there is not enough perspective to conclude. In the literature, for WHO grade I meningiomas, the recurrence rate varies between 5 and 20\% [22]. On the other hand, the recurrence rates of atypical and anaplastic meningiomas are very high (50 to $95 \%$ of cases), regardless of how they are managed, even after radical removal [15,34].

For squamous cysts, the rate of complete excision varies widely in the literature. Yasargil on a series of 22 cases, had total excision in $97 \%$ of cases. He observed no recurrence over a follow-up period of about 6 years. Samii et al. [29] out of a series of 40 cases, had $75 \%$ complete removal rate. And over the same follow-up period, they had a $7.5 \%$ recurrence rate $[35,36]$. We observed only one case of recurrence of squamous cyst two years after surgery. Medulloblastoma is a very rare tumor in APC. There is currently no consensus on ownership. The evolution is mainly marked by recidivism. Jaiswal et al. [37] in a series of 14 cases, 50\% recurred over an average of 6 months of follow-up. In our series, we had two cases, both patients had a recurrence in less than a year, they had a second excision surgery. Like medulloblastoma, the literature on hemangioblastoma in the APC is poor. Out of a series of 23 cases, Cheng et al. [38] had 4 cases of recidivism or $17 \%$ [38]. We had a had a case of CPA hemangioblastoma, he recurred after four years of follow-up.

\section{Limitations of the study}

The size of our cohort is not large and the absence of some data makes it difficult to draw convincing conclusions; however, this is a preliminary study. It was also noted that most clinical and paraclinical classifications were not found in the files and ophthalmological and otological examinations were not performed. This pushes us to harmonize the evaluation of patients. We also note that more than half of the patients did not obtain their anatomopathological results. It takes on average 3 months, in our context, to get the results. Not all patients had an otological evaluation and only 22 patients had a control imaging because of the cost of these examinations. Facial nerve monitoring, and neuronavigation is not available in our unit.

\section{Conclusion}

Surgery of tumors of the cerebellopontine angle is always a challenge in our context. The tumor pathology of this region is dominated by benign, but large, tumors. This aspect increases the morbidity of the surgical procedure in general and especially in our context where we do not have intraoperative monitoring of the cranial nerves. This makes the complete removal of these tumors very morbid and affects the quality of treatment provided. The next step would consist in early detection of its tumors, on the one hand, and on the other hand, to have intraoperative monitoring allowing a complete removal of these tumors with reduced morbidity.

\section{References}

1. Berkowitz O, Iyer AK, Kano H, Talbott EO, Lunsford D, et al. (2015) Epidemiology and environmental risk factors associated with vestibular schwannoma. World Neurosurgery 84(6): 1674-1680.

2. Brackmann DE, Bartels LJ (1980) Rare tumors of the cerebellopontine angle. Otolaryng Head Neck Surg 88: 555-559.

3. De Monte F (1993) Neoplasms and the cranial nerves of the posterior fossa. In: Barrow DL (Ed.) Surgery of the cranial nerves of the posterior fossa. American Association of Neurological Surgeons p. 253-254.

4. Lalwani AK (1992) Meningiomas, epidermoids, and other nonacoustic tumors of the cerebellopontine angle. Otolaryng Clin N Am 25(3): 707728.

5. Claassen AJ (1996) Acoustic neuroma surgery in South Africa. 32nd Annual Congress of the South African Society Otorhinolaryngology Head Neck Surgery and 3rd Congress of the Pan African Federation of Otorhinolaryngological Societies, South Africa.

6. Ohaegbulam S, Okwunodulu O, Ndubuisi C, Mezue W, Chikani M, et al. (2017) Vestibular schwannoma appears to be very rare in a region of Sub-Saharan Africa. Surg Neurol Int 8: 171.

7. Samii M, Gerganov V (2003) Vestibular Schwannomas. In: Samii M, Gerganov V (Eds.) Surgery of cerebellopontine lesions. p.147-314.

8. Samii M, Gerganov V (2003) Meningiomas. In: Samii M, Gerganov V (Eds.) Surgery of Cerebellopontine Lesions. p. 375-508.

9. Sekhar LN, Gormley WB, Wright DC, Kamerer D, Schessel D, et al. (1997) Acoustic neuromas: Results of current surgical management. Neurosurgery 41(1): 50-58.

10. Sekhar LN, Jannetta PJ (1984) Cerebellopontine angle meningiomas. Microsurgical excision and follow-up results. J Neurosurg 60(3): 500505 . 
11. Seedat RY, Claassen AJ, Mol DA (2002) Incidence and management of acoustic neuromas in South Africa. Otol Neurotol 23(6): 996-998.

12. Patel S, Nuño M, Mukherjee D, Nosova K, Lad SP, et al. (2013) Trends in surgical use and associated patient outcomes in the treatment of acoustic neuroma. World Neurosurgery 80: 142-147.

13. Voss NF, Vrionis FD, Heilman FB, Robertson JH (2000) Meningiomas of the cerebellopontine angle. Surgical Neurology 53(5): 439-447.

14. Matthies C, Samii M (1997) Management of 1000 vestibular schwannomas (Acoustic Neuromas): Clinical presentation. Neurosurgery 40(1): 1-9.

15. Nakamura M, Roser F, Dormiani M, Matthies C, Vorkapic P, et al. (2005) Facial and cochlear nerve function after surgery of cerebellopontine angle meningiomas. Neurosurgery 57(1): 77-90.

16. Talfer S, Dutertre G, Conessa C, Desgeorges M, Poncet JL, et al. (2010) Surgical treatment of large vestibular schwannomas (stages III and IV). Eur Ann Otorhinolaryngol Head Neck Dis 127(2): 63-69.

17. Ribas GC, Yassuda A, Rhotin AL (2009) Microsurgical anatomy of the cerebellopontine angle and its suboccipital retromastoid approaches. In: Bambakidis NC, Megerian CA, Spetzler RF (Eds.) Surgery of the cerebellopontine angle. BC Decker p.11-30.

18. Samii M, Gerganov V (2003) Neuropathology of the Cerebellopontine Angle and Its Surroundings. Surgery of Cerebellopontine Lesions p.75113.

19. Ndubuisi CA, Ohaegbulam SC, Iroegbu LU, Ekuma ME, Mezue WC, et al (2017) Histologically confirmed intracranial tumors managed at Enugu, Nigeria. J Neurosci in Rural Practice 8(4): 585-590.

20. Boublata L, Kabache M, Hamrouche N, Ioualalen N (2017) Results of the management of large and large vestibular schwannomas operated by the transmural retro sigmoidal approach in half-sitting position. Neurosurgery 63(1): 31 .

21. Kalamarides M, Rey A, Redondo A, Bozorg-Grayeli A, Sterkers O (2007) Chirurgie des schwannomes vestibulaires solitaires. Neurochirurgie 53(5): 428-429.

22. Agarwal V, Babu R, Grier J, Adogwa O, Back A, et al. (2013) Cerebellopontine angle meningiomas: postoperative outcomes in a modern cohort. Neurosurg Focus 35(6): E10.

23. Bir HC, Patra DP, Maiti TM, Bollam MP, Minagar A, et al. (2017) Direct Comparison of Gamma Knife Radiosurgery and Microsurgery for Small Size Meningiomas. World Neurosurg 101: 170-179.

24. Choi C, Soltys SG, Gibbs IC, Harsh GR, Sakamoto GT, et al. (2011) Stereotactic radiosurgery of cranial nonvestibular schwannomas: results of single-and multisession radiosurgery. Neurosurgery 68(5): 1200-1208.
25. Chung L, Nguyen TP, Sheppard JP, Lagman C, Tenn S, et al. (2018) A systematic review of radiosurgery versus surgery for neurofibromatosis type 2 vestibular schwannomas. World Neurosurg 109: 47-58.

26. Ding D, Starke RM, Kano H, Nakaji P, Barnett GH, et al. (2014) Gamma knife radiosurgery for cerebellopontine angle meningiomas: a multicenter study. Neurosurgery 75(4): 398-408.

27. Sylvester MJ, Shastri DN, Patel VM, Raikundalia MD, Eloy JA, et al. (2017) Outcomes of vestibular schwannoma surgery among the elderly. Otolaryngol Head Neck Surg 156(1): 166-172.

28. Silva J, Cerejo A, Duarte F, Silveira F, Vaz R (2012) Surgical removal of giant acoustic neuromas. World Neurosurg 77(5-6): 629-630.

29. Matthies C, Samii M (1997) Management of 1000 vestibular schwannomas (acoustic neuromas): surgical management and results with an emphasis on complications and how to avoid them. Neurosurgery 40(1):11-23.

30. Kane AJ, Sughrue ME, Rutkowski MJ, Berger MS, McDermott MW, et al. (2011) Clinical and surgical considerations for cerebellopontine angle meningiomas. J Clin Neurosci 18(6): 755-759.

31. Pirouzmand F, Tator CH, Rutka J (2001) Management of hydrocephalus associated with vestibular schwannoma and other cerebellopontine angle tumors. Neurosurgery 48(6): 1246-1254.

32. Langlois AM, Iorio-Morin C, Masson-Côté L, Mathieu D (2017) Gamma Knife stereotactic radiosurgery for non-vestibular cranial nerve schwannomas. World Neurosurg 110: e1031-e1039.

33. Leksell L (1971) A note on the treatment of acoustic tumours. Acta Chir Scand 137(8): 763-765.

34. Wu ZB, Yu CJ, Guan SS (2005) Posterior petrous meningiomas: 82 cases. J Neurosurg 102(2): 284-289.

35. Samii M, Tatagiba M, Piquer J, Carvalho GA (1996) Surgical treatment of epidermoid cysts of the cerebellopontine angle. J Neurosurg 84(1): 14-19.

36. Yasargil MG, Abernathey CD, Sarioglu AÇ (1989) Microneurosurgical treatment of intracranial dermoid and epidermoid tumors. Neurosurgery 24(4): 561-567.

37. Jaiswal AK, Mahapatra AK, Sharma MC (2004) Cerebellopointine angle medulloblastoma. J Clin Neurosci 11(1): 42-45.

38. Cheng J, Liu W, Zhang S, Lei D, Hui X (2017) Clinical features and surgical outcomes in patients with cerebellopontine angle hemangioblastomas: Retrospective series of 23 cases. World Neurosurg 103: 248-256. 